\title{
Analysis of CSTR Temperature Control with Adaptive and PID Controller (A Comparative Study)
}

\author{
Rahul Upadhyay and Rajesh Singla
}

\begin{abstract}
This paper presents the design of a nonlinear feedback controller is analyzed for temperature control of continuous stirred tank reactors (CSTRs) which have strong nonlinearities. Consequently, we need to introduce a control mechanism that will make the proper changes on the process to cancel the negative impact that such nonlinearities may have on the desired operation of chemical plant. A method for adaptive control of a continuous stirred tank reactor with output temperature constraint is developed. The controller is robust to modeling errors and random disturbances occurring in the system. The controller design is analyzed for this situation we use two controller Adaptive and PID and analyzed which controller provide most linear response, The basic PID controllers have difficulty in dealing with problems that appear in complex non-linear processes Simulation studies give satisfactory results.
\end{abstract}

\section{INTRODUCTION}

The design of a nonlinear feedback controller is analyzed for temperature control of continuous stirred tank reactors (CSTRs) which have strong nonlinearities. Consequently, we need to introduce a control mechanism that will make the proper changes on the process to cancel the negative impact that such nonlinearities may have on the desired operation of chemical plant. A method for adaptive control of a continuous stirred tank reactor with output temperature constraint is developed. The controller is robust to modeling errors and random disturbances occurring in the system. The controller design is analyzed for this situation we use two controller Adaptive and PID and analyzed which controller provide most linear response, The basic PID controllers have difficulty in dealing with problems that appear in complex non-linear processes .Simulation studies give satisfactory results. The present work provides a control mechanism for a CSTR. The control objective in this simulation-based work is to maintain the CSTR at steady state operating point. PID controllers are appropriate for the control of non-linear processes. Intuitively an adaptive system has maximum application when the plant undergoes transitions or exhibits non-linear behavior and when the structure of the plant is not known. This permits the controller to maintain a required level of performance in spite of any noise or fluctuation in the process. The basic PID controllers have difficulty in dealing with problems that appear in complex non-linear processes. This work presents a practical non-linear adaptive and PID controller that deals with these non-linear difficulties.

\section{Mathematical Modeling}

The examined reactor has real background and graphical diagram of the CSTR reactor is shown in Figure 1. The mathematical model of this reactor comes from balances inside the reactor. Notice that: a jacket surrounding the reactor also has feed and exit streams. The jacket is assumed to be perfectly mixed and at lower temperature than the reactor. Energy passes through the reactor walls into jacket, removing the heat generated by reaction. The control objective is to keep the temperature of the reacting mixture $\mathrm{T}$, constant at desired value . The only manipulated variable is the coolant temperature.



Fig1. Continues stirred tank reactor with cooling jacket

\subsection{Steady State Solution}

The steady state solution is obtained when $\mathrm{dCA} / \mathrm{dt}=0$ and $\mathrm{dT} / \mathrm{dt}=0$, that is

$f_{l}\left(C_{A}, T\right)=d C_{A} / d t=0=F / V\left(C_{A f}-C_{A}\right)-K o \exp (-E / R T) C_{A} \ldots .(1.1)$

$\left.f_{2}\left(C_{A}, T\right)=d T / d t=0=F / V\left(T_{f}-T\right)+\left(-\Delta H / \rho C_{P}\right) K_{0} \exp (-E / R T) C_{A}\right)-$ $U A / V \rho C_{P}\left(T-T_{j}\right) \ldots \ldots \ldots(1.2)$

To solve these two equations, all parameters and variables except for two $\left(\mathrm{C}_{\mathrm{A}}\right.$ and $\left.\mathrm{T}\right)$ must be Specified

TABLE A. REACTOR PARAMETER'S VALUe

\begin{tabular}{|l|l|}
\hline Reactor parameters & Values \\
\hline $\mathrm{F} / \mathrm{V}, \mathrm{hr}-1$ & 1 \\
\hline $\mathrm{Ko}, \mathrm{hr}-1$ & $10 \mathrm{e} 15$ \\
\hline$(-\Delta \mathrm{H}), \mathrm{kcal} / \mathrm{kmol}$ & 6000 \\
\hline $\mathrm{E}, \mathrm{kcal} / \mathrm{kmol}$ & 12189 \\
\hline
\end{tabular}




\begin{tabular}{|l|l|}
\hline$\rho \mathrm{Cp}, \mathrm{kcal} / \mathrm{m} 3$ 'c & 500 \\
\hline Tf,'k & 312 \\
\hline $\mathrm{Caf}, \mathrm{kmol} / \mathrm{m} 3$ & 10 \\
\hline $\mathrm{UA} / \mathrm{V}$ & 145 \\
\hline Tj,'k & 300 \\
\hline
\end{tabular}

\subsection{Linearization of Dynamic Equation}

The stability of the non-linear equation can be determined by finding the following state space form:

$\mathrm{X}^{\prime}=\mathrm{AX}+\mathrm{BU}$

And determine the eigen values of the A (state space) matrix.

The non-linear dynamic equations are

$\mathrm{F}_{1}\left(\mathrm{C}_{\mathrm{A}}, \mathrm{T}\right)=\mathrm{dC}_{\mathrm{A}} / \mathrm{dt}=\mathrm{F} / \mathrm{V}\left(\mathrm{C}_{\mathrm{Af}}-\mathrm{CA}\right)-\operatorname{koexp}(-\mathrm{E} / \mathrm{RT}) \mathrm{C}_{\mathrm{A}}$ $\mathrm{F}_{2}\left(\mathrm{C}_{\mathrm{A}}, \mathrm{T}\right)=\mathrm{dT} / \mathrm{dt}=\mathrm{F} / \mathrm{V}\left(\mathrm{T}_{\mathrm{f}}-\mathrm{T}\right)+(-\Delta \mathrm{H} / \mathrm{\rho Cp}) \operatorname{koexp}(-$ $\mathrm{E} / \mathrm{RT}) \mathrm{C}_{\mathrm{A}}-\mathrm{UA} / \mathrm{V} \rho \mathrm{Cp}(\mathrm{T}-\mathrm{Tj})$

Let the state and input variables be defined in deviation variable form.

$$
X=\left[\begin{array}{c}
C_{A}-C_{A S} \\
T-T_{S}
\end{array}\right] \quad U=\left[T_{J}-T_{J S}\right] \quad Y=\left[\begin{array}{c}
C_{A}-C_{A S} \\
T-T_{S}
\end{array}\right]
$$

\subsection{Stability Analysis}

Two-state (Jacket Temperature Input) Model .The steadystate operating point is $\mathrm{C}_{\mathrm{As}}=7.5938, T s$, $=313.17$. The stability of particular operating point is determined by finding the A-matrix for that particular operating point and finding the Eigen values of the A-matrix.

$$
A=\left[\begin{array}{cc}
-1.0156 & -0.0979 \\
1.7101 & -0.3145
\end{array}\right]
$$

Then to find the eigenvalues, In Mat lab command we write

$>>$

$\mathrm{A}=[-1.0156,-0.0879 ; 1.7101,-0.3145]$

$>\mathrm{Y}=\operatorname{eig}(\mathrm{A})$;

$>>Y=$

$>>$

Both of the eigenvalues are negative, indicating that the point is stable. similarly we find B,C,D matrix and Once we found the A,B,C,D the transfer function that relate the input to output is obtained by using the Mat lab command.

\section{ADAPTATION LAW}

The adaptation law attempts to find a set of parameters that minimize the error between the plant and the model outputs. To do this, the parameters of the controller are incrementally adjusted until the error has reduced to zero. A number of adaptation laws have been developed to date. The two main types are the gradient and the Lyapunov approach and we have use lyapunov approach.

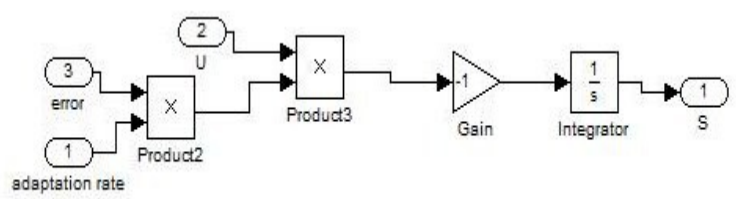

Fig2.Simulink implementation of Lyapunov Adaptation law

\section{AdAPtive CONTROL DESIGN}

This set provides the implementation of a basic adaptive controller using Simulink. The first item that must be defined is the plant that is to be controlled. The simplified transfer function model of the process given as:

$$
\mathrm{G}_{\mathrm{P}} 1(\mathrm{~s})=\frac{2.7 \mathrm{~s}+2.742}{\mathrm{~s}^{2}+1.33 \mathrm{~s}+0.4968}
$$

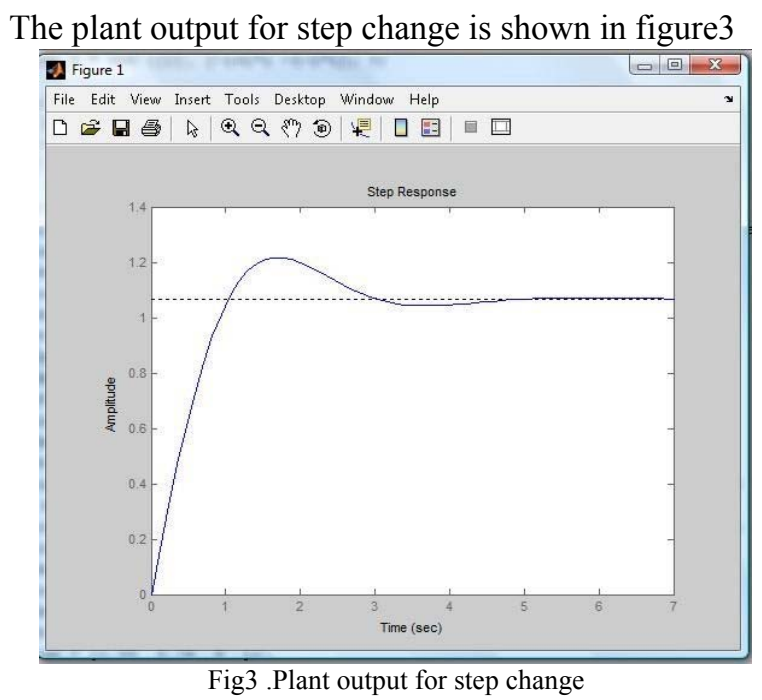

The next step is to define the model that the plant must be matched to. To determine this model we must first define the characteristics that we want the system to have. Firstly we will select the model to be a second order model of the form:

$G m(s)=\frac{n^{2}}{s^{2}+2{ }_{n} \xi s+n^{2}}$

We must then determine the damping ratio $\xi$ and the natural frequency $n$ to give the required performance characteristics. For the concentration control a maximum overshoot (Mp) of 5\% and a settling time (Ts) of less than 3 seconds are selected. Natural frequency from settling time and damping ratio .Based upon formulae we get $\xi=0.713$ and $\omega_{\mathrm{n}}=2.134 \mathrm{rad} / \mathrm{s}$. The transfer function for the model is therefore.

$G m(s)=\frac{4.76}{\mathrm{~S}^{2}+3.1 \mathrm{~s}+4.76} \ldots . .(1.5)$

Equation 1.5 Model transfer function

V. CSTR With AdAPTIVE CONTROL 


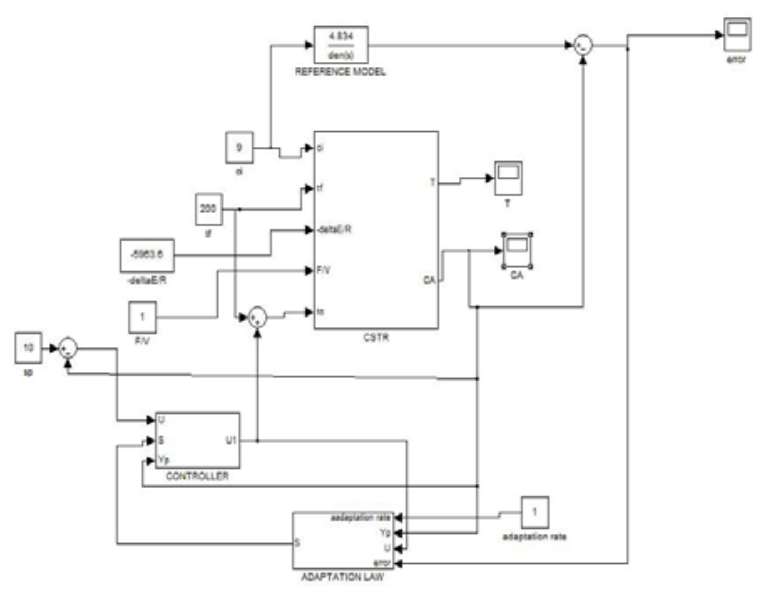

Fig4 .CSTR with Adaptive Control

The operation of the CSTR is disturbed by external factors such as changes in the feed flow rate and temperature .we need to form of control action to alleviate the impact of the changing disturbances and to keep $\mathrm{T}$ and $\mathrm{V}$ only at the desired SP. In this system the manipulated temperature tc is responsible to maintain the temperature $\mathrm{T}$ at the desired SP. The CSTR with adaptive controller is shown in figure 4. The reaction is exothermic and the heat generated is removed by the coolant, which flows in the jacket around the tank. The control objective is to keep the temperature of the reacting mixture, $\mathrm{T}$, constant at a desired SP. The only manipulated variable is the coolant temperature. The control objectives are to ensure the stability of the process, suppressing the influence of external disturbances and optimizing the economic performance of a plant.

\subsection{Concentration output}

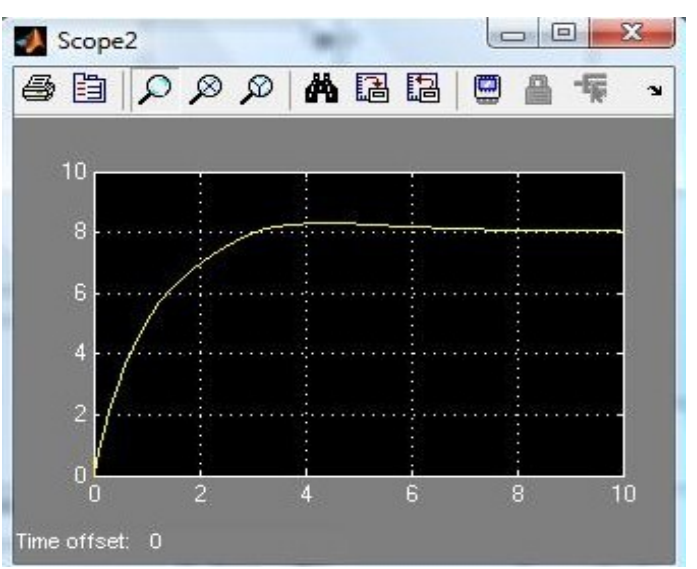

Fig5. Concentration output when $\mathrm{Sp}=7, \mathrm{ci}=8, \mathrm{tf}=300$

\subsection{Temperature output}



Fig6. Temperature output when $\mathrm{Sp}=7, \mathrm{ci}=8, \mathrm{tf}=300$

\subsection{Error}

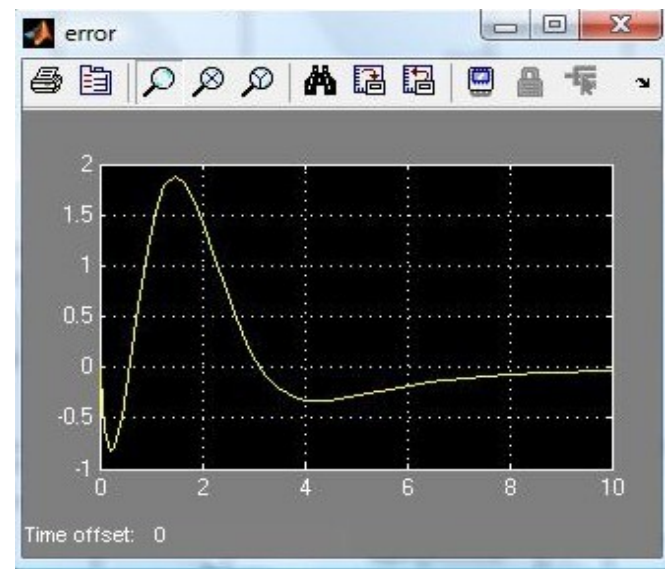

Fig7. Error output when $\mathrm{Sp}=7, \mathrm{ci}=8, \mathrm{tf}=30$

\subsection{Concentration output}

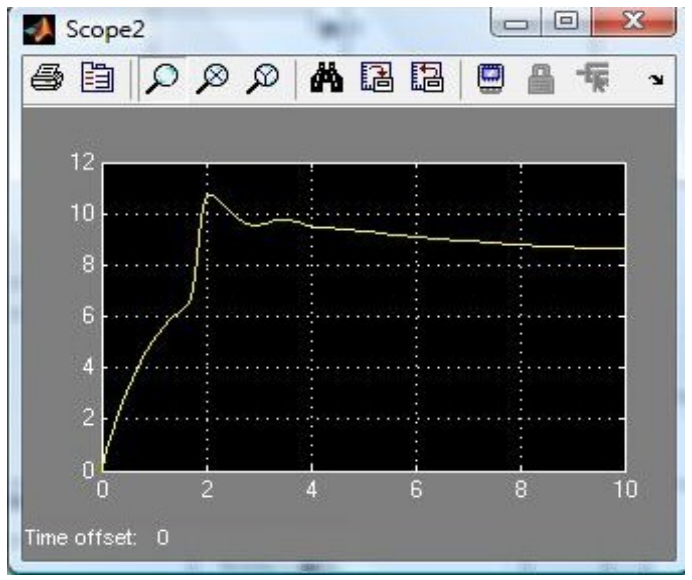

Fig 8. Concentration output when $\mathrm{Sp}=10, \mathrm{ci}=8, \mathrm{tf}=300$

\subsection{Temperature output}




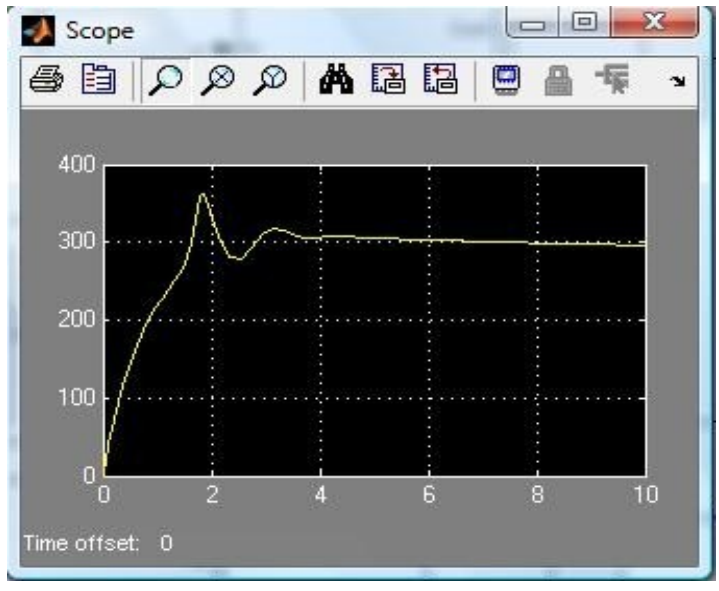

Fig9 . Temperature output when $\mathrm{Sp}=10, \mathrm{ci}=8, \mathrm{tf}=300$

\subsection{Error}



Fig10. Error output when $\mathrm{Sp}=10, \mathrm{ci}=8, \mathrm{tf}=300$

\section{CSTR WITH PID CONTROLLER}

In this process we control the temperature by controlling the concentration, if more concentration is generated that means the temperature inside the reactor is high as that of feed. We have comparison between PID and Adaptive, which is provide most controlled output. The control objective in this simulation-based work is to maintain the CSTR at steady state operating point. The result shown in figure as give the information about concentration and temperature while we changed the set point and concentration and temperature, the tank is considered to be well stirred, which implies that the temperature of the effluent is equal to the temperature of the liquid in the tank. Our aim is to keep the effluent temperature $\mathrm{T}$ at a desired value.

\subsection{Concentration output}



Fig11. Concentration output when $\mathrm{Sp}=7, \mathrm{ci}=10, \mathrm{tf}=150$

\subsection{Temperature output}



Fig12. Temperature output when $\mathrm{Sp}=7, \mathrm{ci}=10, \mathrm{tf}=150$

\subsection{Concentration output}



Fig13. Concentration output when $\mathrm{sp}=10, \mathrm{ci}=8, \mathrm{tf}=300$

\subsection{Temperature output}




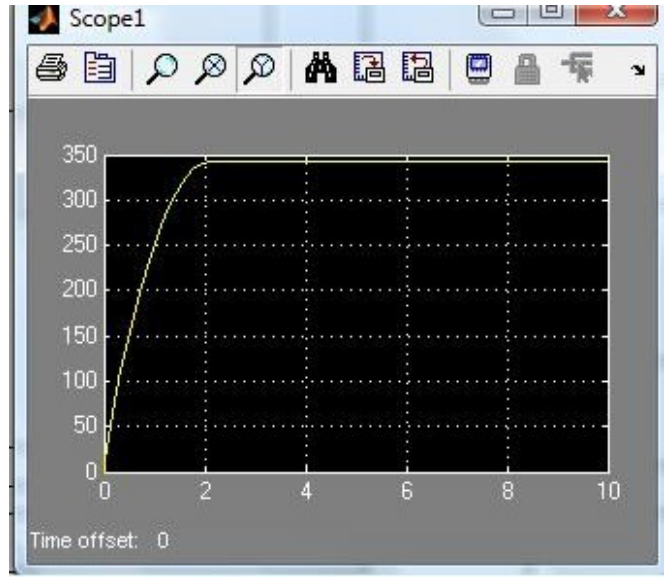

Fig14. Temperature output when $\mathrm{sp}=10, \mathrm{ci}=8, \mathrm{tf}=300$

From these graphs the disadvantage of PID Controller can be seen as it is not maintaining the stability and it has higher response time. i.e. the effluent temperature and concentration is not keep a s a desired value. The PID controller does not ensure the stability of the process, and it is not suppressing the influence of external disturbances

\section{In all figure respected to temperature control shows the they maintain stability as fast as compared to PID}

\section{Controller evaluation:}

\begin{tabular}{|l|l|l|}
\hline Criterion & \multicolumn{1}{|c|}{ PID } & \multicolumn{1}{c|}{ ADAPTIVE } \\
\hline Adaptability & Always Bad & Good \\
\hline stability & Regular & Good \\
\hline Regulation & Bad & Good \\
\hline Settling time & more required & Low as compared to PID \\
\hline Peak overshoot & Low & High \\
\hline Optimal tuning & Easy & Regular \\
\hline
\end{tabular}

\section{CONCLUSION}

The proposed adaptive and PID controller is tested by using Math lab Simulink program and its performance is compared to a different temperature \& concentration. The paper demonstrated that while the adaptive controller exhibits superior control in the presence of nonlinearities. This paper illustrates the control of non-linear system CSTR (Continuous Stirred Tank Reactor). And the results prove that adaptive controllers are appropriate under non-linear difficulties.

\section{APPENDIX}

\begin{tabular}{|l|l|}
\hline Reactor parameters & Description \\
\hline $\mathrm{Ko}, \mathrm{hr}-1$ & exponential factor \\
\hline$(-\Delta \mathrm{H}), \mathrm{kcal} / \mathrm{kmol}$ & heat of reaction \\
\hline $\mathrm{E}, \mathrm{kcal} / \mathrm{kmol}$ & activation energy \\
\hline$\rho \mathrm{Cp}, \mathrm{kcal} / \mathrm{m} 3$ 'c & Density*Heat capacity \\
\hline $\mathrm{Tf}, \mathrm{k}$ & feed temperature \\
\hline $\mathrm{Caf}, \mathrm{kmol} / \mathrm{m} 3$ & Concentration of feed stream \\
\hline $\mathrm{S}$ & Controller initial parameter \\
\hline
\end{tabular}

\section{Lyapunov Rule}

An alternative approach to the MIT rule is to use Lyapunov based method, which avoids the stability problems present in the gradient approaches. A typical adaptation law for a Lyapunov based adaptive controller is shown in equation below.

$$
\mathrm{d} \theta / \mathrm{dt}=-\gamma \mathrm{e} \theta
$$

\section{ACKNOWLEDGMENT}

I would like to express my deep gratitude to my mother laxmi Upadhyay and my father H S Upadhyay for his Love and support on this project. They motivated and helped me to expand my knowledge through self learning .He showed me the importance of research paper and provide right path. I would like to thank Dr. Manoj Sharma to provide continuous help and support to complete my thesis.

\section{REFERENCES}

[1] Middleton R.H., Goodwin, G.C., Hill D.J., and Mayne,D.Q, "Design issues in adaptive control", IEEEtransaction on automatic control, Vol.33, No.1, 1988,pp.50-58.

[2] Taylor, J.H., A\& str\&o\&m K.J., "A non-linear PID auto tuningalgorithm", American Automatic control conference,Seattle, W.A., pp. 1-6, 1986.

[3] S. Ozcelik and H. Kaufman, "Design of MIMO robust direct model reference adaptive controllers," in $36^{\text {th }}$ IEEE Conference on Decision \& Control, (San Diego,CA), pp. 1890

[4] Andreiev, N., "A Process Controller that Adapts to Signal and Process Conditions,"control Engineering, Vol. 38, 1977

[5] K. Y. Rani and K. Gangiah, "Adaptive generic model control," AICHE J., vol. 37, pp. 16341644, 1991

[6] P. A. Ioannou and J. Sun, Robust Adaptive Control, Prentice-Hall, 1996

[7] Astr"om, K. and T. Hagglund, (1995) PID Controllers: Theory Design, and Tuning,2nd Edition, Instrument Society of America.

[8] Mathworks, (1999), Control System Toolbox User's Guide, Natick, The Mathworks Inc.

[9] Adaptive control systems: techniques and applications By V. V Chalam

[10] J.-J. E. Slotine and W. Li: Applied Nonlinear Control. PrenticeHall, Englewood Cliffs, N. J. 1991

[11] Luyben, W. L., "Process Modeling, Simulation and Control for Chemical Engineers", McGraw-Hill, New York, 1989.

[12] Edgar, B., "Stability of Adaptive Controllers", Lecture Notes in Control and Information Sciences, Vol. 20, Springer Verlag, Berlin, 1979.

[13] Fried land B., "Advanced Control System Design", Prentice Hall, New Jersey, 1996.

[14] Bellman, R, "Adaptive Control----A Guided Tour", Princeton University Press, 1961:68-97

[15] Jiri Vojtesek and Petr Dostal, "Simulation analysis of CSTR" Tomas Bata University in Zlin, 1998:22-45

[16] Ioannou and J. Sun, "Robust Adaptive Control", Prentice-Hall, 1996:313-514

[17] K.J. ${ }^{\circ}$ Astr" om and B. Wittenmark, Adaptive control, Addison Wesley, 1995

[18] Seider, W.D., J.D. Seader and D.R. Lewin "Process Design Principles", Wiley (1999).

[19] Adaptive control systems: techniques and applications By V. V. Chalam:34-98.

[20] Isidori, A., "Nonlinear control systems". New York: Springer Verlag, 1995:12-56

[21] R. Marino and P. Tomei, Nonlinear Adaptive DesignGeometric, Adaptive, and Robust, Printice Hall International (UK) Limited, London, 1995.

[22] K. A. and J. C. Kantor, "An exothermic continuous stirred tank reactor is feedback equivalent to a linear system," Chem. Eng. Commum., vol. 37, no. 1, 1985. 
[23] M. Krstic, I. Kanellakopoulos and P. V. Kokotovic, Nonlinear and Adaptive Control Design, New York: Wiey and Sons, 1995

Rahul Upadhyay was born in Agra, INDIA in 1987. He obtained his Engineering degree in Electronics \& Instrumentation in 2008 from the I.E.T Engineering college of Agra and his M.Tech.degree in Control \& Instrumentation from the National Institute of Technology Jalandhar, punjab in 2010. His research interests in control system, adaptive \& process control systems. He also published the one research paper in IEEE conference .

Rajesh Singla obtained his M.tech degree from IIT rorkee. Currently he is pursuing $\mathrm{PhD}$ degree from National Institute of Technology Jalandhar, Punjab. He is working as a lecturer in National Institute of Technology Jalandhar. His area of research in BCI,Process control system. 